\title{
The Usage of CAUSE in Three Branches of Science
}

\author{
Bei Yang ${ }^{1} \&$ Bin Chen ${ }^{2}$ \\ ${ }^{1}$ School of English and Education, Guangdong University of Foreign Studies, Guangzhou, China \\ ${ }^{2}$ International College, Guangdong University of Foreign Studies, Guangzhou, China \\ Correspondence: Bei Yang, School of English and Education, Guangdong University of Foreign Studies, \\ Guangzhou, 510420, China. Tel: 86-20-3932-8080. E-mail: bei_yang@gdufs.edu.cn
}

Received: March 12, 2016

Accepted: April6, $2016 \quad$ Online Published: April 22, 2016

doi:10.5539/hes.v6n2p109

URL: http://dx.doi.org/10.5539/hes.v6n2p109

\begin{abstract}
Semantic prosody is a concept that has been subject to considerable criticism and debate. One big concern is to what extent semantic prosody is domain or register-related. Previous studies reach the agreement that CAUSE has an overwhelmingly negative meaning in general English. Its semantic prosody remains controversial in academic writing, however, because of the size and register of the corpus used in different studies. In order to minimize the role that corpus choice has to play in determining the research findings, this paper uses sub-corpora from the British National Corpus to investigate the usage of CAUSE in different types of scientific writing. The results show that the occurrence of CAUSE is the highest in social science, less frequent in applied science, and the lowest in natural and pure science. Its semantic prosody is overwhelmingly negative in social science and applied science, and mainly neutral in natural and pure science. It seems that the verb CAUSE lacks its normal negative semantic prosody in contexts that do not refer to human beings. The implications of the findings for language learning are also discussed.
\end{abstract}

Keywords: CAUSE, collocation, semantic prosody, scientific writing

\section{Introduction}

The word collocation was brought into its modern form by Firth when he said "I propose to bring forward as a technical term, meaning by collocation, and apply the test of collocability" (Firth, 1957, p. 194). Collocations of a given word are "statements of the habitual or customary places of that word" (Firth, 1968, p. 181). Firth's notion of collocation is essentially quantitative, however. Most linguists today agree that the only way to reliably identify the collocates of a given word or phrase is to study patterns of co-occurrence in a corpus (Sinclair, 1991; Hoey, 1991; Stubbs, 1995; Partington, 1998; McEnery \& Wilson, 2001; Hunston, 2002; Sinclair et al., 2004).

A closely related concept is semantic prosody which is initially defined as a "consistent aura of meaning with which a form is imbued by its collocates" (Louw, 1993, pp. 156-159). Louw illustrates semantic prosody with the examples of utterly, bent on and symptomatic of, which are followed by expressions referring to undesirable things (such as destroying, ruining, clinical, depression, multitudeof sins, etc.). Although the term "semantic prosody" was first used by Louw (1993), it was attributed to Sinclair (1991) who shows that the phrasal verb set in occurs primarily with subjects which refers to unpleasant states of affairs, such as rot, decay, malaise, despair, ill-will and decadence.

Semantic prosody is a concept rooted in the neo-Firthian concordance-based analysis of collocation. For example, Stubbs (1996, p. 176) states that semantic prosody is a particular collocational phenomenon and classifies it into three categories: negative prosody, positive prosody and neutral prosody. The node word bears a strong negative prosody if its collocates are mainly of strong negative semantic characteristics. The node word bears a strong positive prosody if its collocates are mainly of strong positive semantic characteristics. If both positive and negative collocates exist in the context, the node word can be said to bear a neutral or mixed prosody. Some words have a predominantly negative prosody. For example, incidence typically collocates with words referring to diseases or defects, such as infections, HIV, injury, colon cancer, defects, disruption, cracking, and so on (Wei, 2002a). A few words have a positive prosody, for example, provide mainly collocates with words related to services or help, such as facilities, information, services, aid, assistance, help, support, care, food, money, nourishement, protection, security, and so on (Stubbs, 1995). Many words are neutral or mixed in this respect. The main collocates of probability of can be divided into three categories: neutral collocates, such as percent, 
change, occurrence and prototype structure; positive collocates, such as success, survival, acquisition, and winning; negative collocates, such as failure, accidents, error, loss, malfunction, and deficiency (Wei, 2002b). Both individual words and phrases can have semantic prosodies (Schmitt \& Carter, 2004, p. 7).

Semantic prosody is also a concept that has been subject to considerable criticism and debate (Partington, 2004; Whitsitt, 2005; Hunston, 2007; Stewart, 2009). One big concern is to what extent semantic prosody is register-related. This paper will investigate the collocational behaviour and semantic prosody of the verb CAUSE in three branches of scientific writing in order to shed new insights into the important yet controversial notion in modern linguistics. The results of the study, therefore, may have implications for EAP (English for Academic Purposes).

\section{Previous Studies on CAUSE}

The word CAUSE is famous in the studies of semantic prosody. The initial investigation can be traced back to Stubbs. When examining the usage of CAUSE in 1-million-word corpus Brown, Stubbs (1995) documented the lexical set of its collocates by constructing a concordance of all occurrences of this word. Nearly $80 \%$ of occurrences are negative (such as cause of death, cause breakage, cause anxiety, cause errors, etc.); $18 \%$ are neutral (such as caused the removal of the pulpit to the side, caused the fantail to start revolving, etc.); $2 \%$ are positive (such as caused such widespread interest, caused a pleasurable mental state, caused him to smile, a cause to display such amiability, etc). Stubbs (ibid) then investigated the usage of cause in a 120-million-word Cobuild corpus, which confirms the negative prosody that CAUSE has.

Wei (2002b) studied CAUSE in a 4 million words Academic English corpus (JDEST) by examining its collocates. The research produced 52 significant collocates of CAUSE, all of which refer to problems, accidents, errors, diseases, or other negative factors in specialized fields (such as failure, bleeding, damage, death, unemployment, injury, trouble, problems, disruption, harm, worry, deterioration, etc.).

Xiao and McEnery (2006) investigated CAUSE in FLOB and Frown, each of which contains approximately one million words. Their study produced 287 instances of CAUSE used as a verb. Of these, 223 occurrences have a negative prosody, 56 are neutral and only 8 cases are positive. The neutral use of CAUSE typically occurs in academic prose which provides 28 out of 56 neutral occurrences (e.g., these echoes are caused by reflection of the speaker's voice back from the distant receiving end... ). Besides, the apparently neutral or even positive occurrences of CAUSE are often offset by their longer co-texts (e.g., that idea caused a brief, groundless burst of hope which brought her a little closer to real waking).

Hunston (2007) compared the usage of CAUSE in general corpus (the Bank of English) and that in academic corpus (the journal New Scientist corpus). In general corpus, the caused entities are either illnesses or symptoms (suffered by people), or emotions such as anger, confusion, frenzy (experienced by people), or processes or abstractions involving people and their goals (fragmentation, rift, problem). However, in academic corpus, the caused entities comprise inanimate entities or processes involving inanimate objects (signal, alpha Lyman line, changes, convection). No particular attitude can be discerned towards the entity brought into being, even when an extended context is shown (e.g., these proteins cause a smell to become less strong if we continue to sniff at it). Hunston (2007) thus argues that semantic prosody is correlated with register.

Previous studies have confirmed that CAUSE has a negative prosody in general English. However, different research produced different results concerning the semantic prosody of CAUSE in academic English, which may be related to the size and register of the corpus used in different studies. In order to minimize the role that corpus choice had to play in determining the research findings, we decided to use British National Corpus (BNC) as data which is big enough and contains different registers of academic English.

\section{Method}

\subsection{Corpus Data}

BNC is a 100 million word collection of samples of written and spoken language from a wide range of sources, which is designed to represent a wide cross-section of British English from the later part of the 20th century, both spoken and written (Aston \& Burnard, 1998). The written part of the BNC (90\%) includes extracts from regional and national newspapers, specialist periodicals and journals for all ages and interests, academic books and popular fiction, published and unpublished letters and memoranda, school and university essays, among many other kinds of text. The spoken part (10\%) consists of orthographic transcriptions of unscripted informal conversations and spoken language collected in different contexts, ranging from formal business or government meetings to radio shows and phone-ins. The present study investigates the usage of CAUSE as a verb in three domains for written corpus texts respectively: social science, applied science, natural \& pure science. 


\subsection{Corpus Tool}

The corpus tool used in this study is the Sketch Engine (SkE) online interface, which falls into the category of fourth-generation concordancers (McEnery \& Hardie, 2012). Corpora in SkE are often annotated with additional linguistic information, the most common being part of speech information (for example, whether something is a noun or a verb), which allows large-scale grammatical analyses to be carried out. As a leading corpus tool, SkE is widely used in lexicography, language teaching, translation and the like (Kilgarriff et al., 2004, 2014). The SkE online interface allows users to search for exact words or phrases, wildcards, lemmas, part of speech, or any combinations of these. One can also search for collocates within a ten-word window (e.g., all nouns, all adjectives, or all verbs near a search word).

\subsection{Analytic Procedures}

Concordance enables researchers to compare frequencies of CAUSE in three branches of science. The first step is thus to conduct the concordance of CAUSE in three domains of BNC: social science, applied science, and natural \& pure science. The next step is to calculate collocates of CAUSE in different branches. The span (the number of words left and right of the search word) is $(-5,5)$, the minimum frequency of each collocate being set 5 and minimum frequency in given range (in our case $-5,5) 3$. Of seven measures to calculate the strength of collocation (T-score, MI, MI3, log likelihood, min. sensitivity, and LogDice), I choose the default one $\log$ Dice which is considered more reliable than the frequently used MI (Mutual Information) measure. The final step is to examine the context of the fifty top collocates to make sure whether it is negative or positive so that the percentage of each type of semantic prosody can be calculated.

\section{Results and Analysis}

\subsection{The Frequency of CAUSE in Three Branches of Science}

Table 1 indicates that the occurrence of CAUSE changes over different domains of science, its frequency in social science being much higher than that in pure science.

Table 1. Frequency of CAUSE in three branches of science

\begin{tabular}{lccc}
\hline & social science & applied science & natural \& pure science \\
\hline Total & 3,632 & 2,759 & 1,491 \\
Per million & 32.38 & 24.59 & 13.29 \\
\hline
\end{tabular}

\subsection{The Collocates and Semantic Prosody of CAUSE in Social Science}

Table 2 lists the top 50 collocates of the verb CAUSE in social science automatically generated by the SkE. Further examination suggests that 38 out of $50(76 \%)$ significant collocates of CAUSE are negative: damage, harm, injury, distress, negligence, nuisance, difficulty, grievous, reckless, confusion, disruption, inconvenience, loss, death, handicap, offence, suffering, serious, delay, accident, defect, injustice, obstruction, alarm, severe, problem, hardship, odour, anxiety, illness, unnecessary, friction, harassment, manslaughter, disease, disturbance, disorder and infection.

Table 2. The top 50 collocates of CAUSE in social science

\begin{tabular}{llllllll}
\hline Rank & Collocates & Freq & $\operatorname{logDice}$ & Rank & Collocates & Freq & $\operatorname{logDice}$ \\
\hline 1 & damage & 280 & 9.292 & 26 & injustice & 18 & 7.077 \\
2 & harm & 126 & 9.231 & 27 & obstruction & 17 & 7.051 \\
3 & injury & 188 & 9.159 & 28 & alarm & 26 & 7.025 \\
4 & distress & 61 & 8.57 & 29 & severe & 32 & 6.999 \\
5 & bodily & 44 & 8.306 & 30 & intentionally & 15 & 6.991 \\
6 & negligence & 35 & 7.869 & 31 & problem & 230 & 6.988 \\
7 & nuisance & 33 & 7.857 & 32 & hardship & 17 & 6.962 \\
8 & difficulty & 116 & 7.836 & 33 & odour & 17 & 6.934 \\
\hline
\end{tabular}




\begin{tabular}{llllllll}
\hline 9 & grievous & 27 & 7.818 & 34 & plaintiff & 28 & 6.933 \\
10 & intent & 38 & 7.796 & 35 & anxiety & 25 & 6.929 \\
11 & reckless & 27 & 7.728 & 36 & illness & 27 & 6.91 \\
12 & confusion & 39 & 7.607 & 37 & unnecessary & 20 & 6.909 \\
13 & disruption & 27 & 7.593 & 38 & friction & 15 & 6.891 \\
14 & inconvenience & 24 & 7.572 & 39 & concern & 67 & 6.889 \\
15 & loss & 107 & 7.534 & 40 & harassment & 15 & 6.861 \\
16 & death & 134 & 7.404 & 41 & permit & 30 & 6.843 \\
17 & handicap & 29 & 7.4 & 42 & smoking & 19 & 6.825 \\
18 & offence & 49 & 7.382 & 43 & indirectly & 16 & 6.811 \\
19 & suffering & 26 & 7.311 & 44 & manslaughter & 14 & 6.793 \\
20 & mental & 44 & 7.269 & 45 & physical & 44 & 6.785 \\
21 & serious & 74 & 7.269 & 46 & disease & 48 & 6.78 \\
22 & delay & 45 & 7.268 & 47 & disturbance & 17 & 6.764 \\
23 & driving & 29 & 7.254 & 48 & disorder & 20 & 6.747 \\
24 & accident & 51 & 7.134 & 49 & infection & 23 & 6.743 \\
25 & defect & 23 & 7.127 & 50 & likely & 87 & 6.742 \\
\hline
\end{tabular}

These examples of unpleasant company collocate with CAUSE so frequently that the typical use of this word shows a negative affective meaning, as shown in (1) to (5).

(1) There was evidence that the book, if published, would almost certainly come to her attention, and would cause her gross psychological damage.

(2) It is not in the public interest that people should try to cause or should cause each other actual bodily harm for no good reason.

(3) The House of Lords accepted that the definitions of the two offences are the same, merely adding that the prosecutor should charge manslaughter when the maximum penalty for the offence of causing death by reckless driving (five years) might be insufficient.

(4) But admirable as this bon mot may be, the widespread use of the necessary techniques is causing some anxiety.

(5) A second virus, HIV 2, was discovered in 1986 and is mainly found in West Africa. HIV 2 may not have as great a potential to cause illness as HIV 1.

12 out of 50 (24\%) significant collocates of CAUSE in social science are neutral: bodily, intent, mental, driving, intentionally, plaintiff, concern, permit, smoking, indirectly, physical and likely. Four of the above neutral collocates (bodily, mental, driving and physical) tend to (from $89 \%$ to 100\%) appear with words of unpleasant meanings. For instance, bodily harm (injury), mental handicap (disorder, disabilities, damage, defect, disease, suffering, problems, frailty), reckless (dangerous, negligent) driving, physical (deterioration, harm, injury, damage, handicap, disabilities, discomfort, pain, etc.). These negative collocations render the occurrences of CAUSE negative meanings, as shown in (6) and (7). In these two examples, bodily and mental appears quite neutral. Nevertheless, the neutrality is immediately traded off by harm and handicap.

(6) By allowing an intent to cause grievous bodily harm to suffice for a murder conviction, the law is violating a general principle, turning the most serious of its offences into a constructive crime.

(7) Mental handicap can be caused by a wide range of medical, social and environmental factors, of which some are to an extent preventable.

Besides, six other neutral collocates (intent, intentionally, plaintiff, smoking, indirectly, and likely) are always (from $66 \%$ to $100 \%$ ) used in construction of negative meanings. For instance, intent to cause harm (injury, loss), intentionally (or recklessly) cause death (injury, violent, battery, suffering, damage, detriment, loss), cause damage (injury, problems, loss, injustice, damnum) to (for) the plaintiff, smoking cause death (cancer, fatal 
diseases, bronchitis, illness), accident (legal liability, injury, disease, risk)... (directly or) indirectly caused by, likely to cause loss (damage, danger, confusion, problems, stress, suffering). The seemingly neutral occurrences of CAUSE are often offset by these negative constructions, as shown in (8) and (9).

(8) In Savage (1990) 91 Cr App R 317, the same court (but a different division) on the same day said that intentionally or recklessly causing a battery was sufficient, as long as actual bodily harm occurred.

(9) Smoking causes six times as many premature deaths as road accidents, all other accidents, suicides, murder, manslaughter, fires, illicit drug use and AIDS put together.

However, when CAUSE collocates with concern and permit, the meanings of the occurrences can be negative (examples 10 and 12) as well as neutral (examples 11 and 13). In (10), concern appears neutral, but the neutrality is immediately traded off by the extended context losses of women on graduate management training programmes are high. Similarly, the neutrality of permits in (12) is offset by nuisance to continue. In (11) and (13), the extended contexts show that the meanings of concern and permit are neutral.

(10) Losses of women on graduate management training programmes are high, -Unilever lost 75 per cent within 5 years-causing special concern.

(11) ALTHOUGH relationships with parents determine in large measure our longer-term preferences, attitudes and values, during adolescence it is often relationships with friends that cause most concern and which pre-occupy the thoughts of young people as they grow up.

(12) It is said, therefore, that it directly causes or permits the nuisance to continue, as happened in Halsey's case.

(13) It is an obtaining of services where the other is induced to confer a benefit by doing some act, or causing or permitting some act to be done, on the understanding that the benefit has been or will be paid for.

From the above analysis, we can see CAUSE is overwhelmingly (96\%) negative in social science.

\subsection{The Collocates and Semantic Prosody of CAUSE in Applied Science}

As shown in Table 3, 29 out of 50 (58\%) significant collocates of CAUSE in applied science are negative: damage, pollution, virus, diarrhea, cancer, severe, disease, symptom, disturbance, bacterium, havoc, disruption, harm, inflammation, infection, lesion, stress, hepatitis, problem, overflow, confusion, tumour, hypergastrinaemium, toxic, erosion, vomit, error, delay and injury.

Table 3. The top 50 collocates of CAUSE in applied science

\begin{tabular}{lllllllr}
\hline Rank & Collocates & Freq & logDice & Rank & Collocates & Freq & logDice \\
\hline 1 & damage & 188 & 8.806 & 26 & hepatitis & 11 & 6.715 \\
2 & pollution & 60 & 8.154 & 27 & problem & 187 & 6.711 \\
3 & virus & 30 & 7.696 & 28 & overflow & 11 & 6.71 \\
4 & diarrhea & 20 & 7.55 & 29 & confusion & 18 & 6.697 \\
5 & cancer & 41 & 7.498 & 30 & stricture & 10 & 6.676 \\
6 & severe & 39 & 7.447 & 31 & pancreatic & 10 & 6.653 \\
7 & disease & 69 & 7.394 & 32 & intestinal & 11 & 6.647 \\
8 & symptom & 33 & 7.392 & 33 & tumour & 13 & 6.608 \\
9 & liver & 22 & 7.334 & 34 & condensation & 9 & 6.574 \\
10 & radiation & 22 & 7.313 & 35 & environmental & 32 & 6.556 \\
11 & chronic & 21 & 7.273 & 36 & hypergastrinaemium & 8 & 6.527 \\
12 & acid & 34 & 6.998 & 37 & acute & 14 & 6.509 \\
13 & disturbance & 16 & 6.946 & 38 & toxic & 11 & 6.499 \\
14 & bacterium & 15 & 6.904 & 39 & erosion & 11 & 6.483 \\
15 & pylorus & 14 & 6.883 & 40 & ozone & 11 & 6.478 \\
16 & havoc & 11 & 6.864 & 41 & NSAIDs & 8 & 6.476 \\
\hline
\end{tabular}




\begin{tabular}{llllllll}
\hline 17 & bile & 14 & 6.852 & 42 & vomit & 9 & 6.475 \\
18 & disruption & 13 & 6.844 & 43 & dose & 14 & 6.469 \\
19 & harm & 21 & 6.842 & 44 & reduction & 24 & 6.466 \\
20 & secretion & 13 & 6.836 & 45 & gastric & 13 & 6.461 \\
21 & warming & 12 & 6.811 & 46 & error & 23 & 6.441 \\
22 & inflammation & 11 & 6.803 & 47 & mucosal & 9 & 6.415 \\
23 & infection & 21 & 6.803 & 48 & delay & 22 & 6.374 \\
24 & lesion & 12 & 6.789 & 49 & injury & 25 & 6.37 \\
25 & stress & 37 & 6.761 & 50 & widespread & 15 & 6.36 \\
\hline
\end{tabular}

When these unpleasant companies collocate with CAUSE, the occurrences show negative meanings, as shown in (14) to (18).

(14) The closures could cause severe damage to hundreds of miles of streams and rivers, the NRA claims.

(15) Researchers at the University of Warwick have found that Salmonella typhimurium, a bacterium that causes diarrhoea, survives for much longer than three weeks, but in a dormant state that makes it much more difficult to detect.

(16) This concentration of fish causes social stress, disease and oxygen depletion, which may in turn cause high mortality rates especially in hot weather.

(17) The National Rivers Authority is to close a loophole under which the 12,000 sewage works in England and Wales can cause highly toxic pollution of rivers without fear of prosecution.

(18) Often one simple fault, for example an incorrect protection on a storage account, can cause many errors to be reported.

21 out of $50(42 \%)$ significant collocates of CAUSE in applied science are neutral: liver, radiation, chronic, acid, pylorus, bile, secretion, warming, stricture, pancreatic, intestinal, condensation, enviromental, acute, ozone, NSAIDs, dose, reduction, gastirc, mucosal and widespread.

10 of the above neutral collocates (liver, chronic, pylorus, warming, pancreatic, enviromental, acute, ozone, mucosal and widespread) always (from $70 \%$ to 100\%) appear with words of unpleasant meanings. For instance, liver damage (malfunction, disease, failure, injury), chronic pancreatitis (enteritis, blood loss, constipation, enterocutaneous fistulas, lymphocytic leukaemia, gastrointestinal symptoms, anxiety), $H$ pylori infection, global warming, pancreatic hyperplasia (fistula, toxicity), enviromental damage (destruction, devastation, degradation, pollution), acute pancreatitis (abdominal pain, tubulardysfunction, papillarynecrosis, gastroenteritis, complication, infections), damage to (depletion of) theozone layer, mucosal damage (injury, losses, abnomalities, hyperplasia), widespread air pollution (smogs, environmental damage, unintentional deaths, inflation, anguish).

These negative collocations render the occurrences of CAUSE negative meanings, as shown in (19) and (20). In these two examples, liver and warming appears quite neutral. Nevertheless, the neutrality is immediately traded off by injury and global.

(19) Patients were stratified according to whether recurrent HBV caused severe, progressive liver injury, including cirrhosis, or mild liver disease (see Table 3).

(20) It warns that ever more land will be needed for crop production, while the land surface is shrinking as a result of rising sea levels caused by global warming.

Besides, although 3 other collocates are neutral (radiation, stricture, and condensation), these words always (from $91 \%$ to $100 \%$ ) appear in longer co-texts of negative meanings. The extended contexts render the occurrences of CAUSE negative meanings, as shown in (21) and (22).

(21) This study aimed to evaluate various aspects of gastrointestinal function in patients with diarrhoea caused by chronic radiation enteritis and the effects of treatment with the peripheral opiate agonist precursor loperamide-N-oxide.

(22) Insulation in lofts which has blocked the natural ventilation of the roof at the eaves can cause condensation and wreak damage as great as the heaviest gales, but with no insurance to cover it. 
However, when CAUSE collocates with acid, bile, secretion, intestinal, dose, reduction and gastirc, the meanings of the occurrences can be negative (23 and 25), as well as neutral (24 and 26). In (23), acid and intestinal appears neutral, but the neutrality is immediately traded off by the extended context emissions of pollutants which cause acid rain. In (24), a process involving inanimate objects is depicted, which is neutral in affective meaning.

(23) The government will ensure power stations meet EC requirements for reduced emissions of pollutants which cause acid rain.

(24) Here it is interesting to note that intrajejunal beer stimulated acid release without causing gastrin release.

(25) The results of Brunsson's study and the present one indicate that intramural reflex(es) are involved in the fluid secretion caused by intestinal inflammation.

(26) There was only a slight but statistically not significant decrease in HCO 3-absorption caused by vasoactive intestinal polypeptide.

From the above analysis, we can see that CAUSE is overwhelmingly (86\%) negative in applied science.

\subsection{The Collocates and Semantic Prosody of CAUSE in Natural \& Pure Science}

When examining collocates in Table 4, it is found that only 21 out of $50(42 \%)$ significant collocates of CAUSE in natural and pure science are negative: infection, deformation, paralysis, damage, extinction, mortality, severe, virus, disease, subsidence, swelling, senescence, enteritis, distress, abnormality, distortion, displacement, erosion, pathogenic, syphilis and diarrhoea.

Table 4. The top 50 collocates of CAUSE in natural and pure science

\begin{tabular}{llllllll}
\hline Rank & Collocates & Freq & logDice & Rank & Collocates & Freq & logDice \\
\hline 1 & mutation & 17 & 7.849 & 26 & bacterium & 8 & 6.53 \\
2 & infection & 29 & 7.601 & 27 & mammalian & 5 & 6.522 \\
3 & deformation & 10 & 7.567 & 28 & aggregation & 5 & 6.519 \\
4 & paralysis & 8 & 7.27 & 29 & tissue & 12 & 6.497 \\
5 & damage & 58 & 7.249 & 30 & gene & 15 & 6.446 \\
6 & compaction & 7 & 7.168 & 31 & anti-peptide & 4 & 6.434 \\
7 & extinction & 9 & 7.132 & 32 & stimulation & 6 & 6.416 \\
8 & mortality & 14 & 6.929 & 33 & mycobacterium & 4 & 6.411 \\
9 & DNA & 17 & 6.836 & 34 & curvature & 5 & 6.402 \\
10 & severe & 21 & 6.828 & 35 & glaciations & 4 & 6.396 \\
11 & heating & 12 & 6.824 & 36 & displacement & 5 & 6.393 \\
12 & virus & 12 & 6.823 & 37 & erosion & 7 & 6.375 \\
13 & disease & 41 & 6.786 & 38 & bacillus & 4 & 6.353 \\
14 & subsidence & 6 & 6.786 & 39 & pathogenic & 4 & 6.342 \\
15 & swelling & 6 & 6.781 & 40 & localized & 4 & 6.333 \\
16 & organism & 11 & 6.779 & 41 & accumulation & 6 & 6.319 \\
17 & senescence & 5 & 6.731 & 42 & rearrangement & 4 & 6.285 \\
18 & larva & 7 & 6.723 & 43 & neurone & 4 & 6.28 \\
19 & enteritis & 5 & 6.719 & 44 & lithosphere & 4 & 6.267 \\
20 & distress & 10 & 6.716 & 45 & orbit & 6 & 6.264 \\
21 & abnormality & 7 & 6.694 & 46 & precipitation & 4 & 6.25 \\
22 & uplift & 6 & 6.685 & 47 & oscillation & 4 & 6.244 \\
23 & distortion & 7 & 6.57 & 48 & syphilis & 4 & 6.224 \\
24 & gravitational & 6 & 6.563 & 49 & diarrhoea & 5 & 6.199 \\
25 & limb & 9 & 6.559 & 50 & proliferation & 5 & 6.198 \\
\hline & & & & & & &
\end{tabular}


Examples with typical negative prosody are shown in (27) to (31):

(27) More serious mental and physical deterioration may follow-Injecting can cause infection leading to sores, abscesses, jaundice and blood poisoning.

(28) Most of these are thought to have rifted away from the margins of Gondwana and moved northward before colliding with the southern margin of the Eurasian land mass and causing extensive deformation and thrusting.

(29) The argument was not that mutation itself caused senescence, but rather that, given some mutation load, the adaptive evolution of modifiers would shift the effects of that load to later life.

(30) In addition, diagnostic delay causes considerable distress to families and may result in subsequent bitterness if the child's symptoms are not taken seriously by family or health professionals or if a second affected boy is born.

(31) Furthermore, the mycobacteria detected in Crohn's disease were not identical, suggesting that a single pathogenic mycobacterium does not cause the disease.

29 out of the $50(58 \%)$ significant collocates of CAUSE in natural and pure science are neutral: mutation, compaction, DNA, heating, organism, larva, uplift, gravitational, limb, bacterium, mammalian, aggregation, tissue, gene, anti-peptide, stimulation, mycobacterium, curvature, glaciations, bacillum, localized, accumulation, rearrangement, neurone, lithosphere, orbit, precipitation, oscillation and proliferation.

Although some collocates are neutral (such as larva and mammalian), these words only appear in longer co-texts of negative meanings, as shown in (32). When CAUSE collocates with the remaining 27 words, the occurrences can be negative (as in 33, 35 and 37) as well as neutral (as in 34, 36 and 38).

(32) A number of genes have been identified as inducible in mammalian cells by agents that cause DNA damage and growth arrest.

(33) Once a mutation that causes an abnormality is observed, it becomes possible to try and identify and isolate the gene.

(34) In fact, genetical analysis of plant "ecotypes" (i.e., populations adapted to a particular habitat, for example growing close to the sea) shows that sometimes rather few gene mutations can cause most of the morphological change.

(35) After about four to six weeks, when the temperature has dropped to about $41^{\circ} \mathrm{C}$, the heap should be turned, when a further surge of bacterial activity and a second heating will take place, causing further breakdown of the vegetable matter.

(36) Fluctuations in temperature experienced by rocks at the Earth's surface due to day-time heating and night-time cooling certainly cause them to expand and contract.

(37) Identifying the specific new mutation in a particular gene that causes a given inherited disease in a patient.

(38) Natural selection favoured those ancestral caddis genes that caused their possessors to build effective houses.

From the above analysis, we can see that CAUSE is mainly neutral in natural and pure science, which can be reaffirmed by the 25 random samples of CAUSE occurrences in natural and pure science.

\section{Conclusion}

This paper has explored the usage of the verb CAUSE in scientific writing in British National Corpus with SkE. The results show that the occurrences of CAUSE is the highest in social science, less frequent in applied science, and the lowest in natural and pure science. The semantic prosody of this word is overwhelmingly negative in social science $(96 \%)$ and applied science $(86 \%)$, the caused entities being either illnesses or symptoms (such as disease, infection, diarrhea, etc.), or negative emotions (such as distress, anxiety, confusion, etc.), or unpleasant conditions (such as difficulty, injustice, error, etc.). However, CAUSE is mainly neutral in natural and pure science (54\%), the caused entities being inanimate objects (such as DNA, bacterium, tissue, etc.), or processes (such as mutation, compaction, oscillation, etc.). It seems that CAUSE lacks its normal negative semantic prosody in contexts that do not refer to human beings, which has echoed the insight of Hunston (2007) in that the presence of a semantic prosody may be dependent on the presence of some other grammatical or semantic feature alongside the node.

This study has a number of pedagogical implications. First, since inappropriate word choice arising from an ignorance of collocation and semantic prosody is very frequent in L2 English learners, the importance of 
collocation and semantic prosody should be emphasized in language teaching and learning (cf., also Hoey, 2000). Second, learners should be aware of the fact that collocational behaviour and semantic prosody of the same word can vary across text categories. This observation is relevant to the teaching and learning of EAP in that different disciplines may have more specific usage regarding a certain word like CAUSE. Third, given the huge amount of English vocabulary, it would be unlikely for teachers to teach the collocational behaviour and semantic prosody of all the words to students. It might be more promising to teach students how to use corpora and corpus tools to conduct their own research.

\section{Acknowledgements}

The study is supported by 1) Innovative School Project in Higher Education of Guangdong, China (GWTP-BS-2014-13) to BY; 2) Foundation for Outstanding Young Teachers, Guangdong Province (GWTP-SY-2014-08) to BY; and 3) Chinese students' language preparation for overseas study (S2013010014016) sponsored by Guangdong Natural Science Foundation to BC.

\section{References}

Aston, G., \& Burnard, L. (1998). BNC Handbook: Exploring the British National Corpus with SARA. Edinburgh: Edinburgh University Press.

Firth, J. (1957). Papers in Linguistics. Oxford: OxfordUniversity Press.

Firth, J. (1968). In F. R. Palmer (Ed.), Selected Papersof J. R. Firth 1952-1959. London: Longman.

Hoey, M. (1991). Pattern of Lexis in Text. Oxford: Oxford University Press.

Hoey, M. (2000). A world beyond collocation: New perspectives on vocabulary teaching. In M. Lewis (Ed.), Teaching Collocations (pp. 224-245). Hove: Language Teaching Publication.

Hunston, S. (2002). Corpora in Applied Linguistics. Cambridge: Cambridge University Press. http://dx.doi.org/10.1017/CBO9781139524773

Hunston, S. (2007). Semantic prosody revisited. International Journal of Corpus Linguistics, 122(2), 249-268. http://dx.doi.org/10.1075/ijcl.12.2.09hun

Kilgarriff, A., Rychly, P., Smrz, P., \& Tugwell, D. (2004). The Sketch Engine. Proc Euralex, Lorient, France.

Kilgarriff, A., Baisa, V., Bušta, J., Jakubíček, M., Kovář, V., Michelfeit, J., ... Suchomel, V. (2014). The Sketch Engine: Ten years on. Lexicography, 1, 7-36. http://dx.doi.org/10.1007/s40607-014-0009-9

Louw, B. (1993). Irony in the text or insincerity in the writer? The diagnostic potential of semantic prosodies. In M. Baker, G. Francis, \& E. Tognini-Bonelli (Eds.), Text and Technology: In Honour of John Sinclair (pp. 157-176). Amsterdam: John Benjamins. http://dx.doi.org/10.1075/z.64.11lou

McEnery, T., \& Hardie, A. (2012). Corpus Linguistics: Method, Theory and Practice. Cambridge: Cambridge University Press.

McEnery, T., \& Wilson, A. (2001). Corpus Linguistics (2nd ed.). Edinburgh: Edinburgh University Press.

Partington, A. (1998). Patterns and Meanings. Amsterdam: John Benjamins. http://dx.doi.org/10.1075/scl.2

Partington, A. (2004). "Utterly content in each other's company": Semantic prosody and semantic preference. International Journal of Corpus Linguistics, 9(1), 131-156. http://dx.doi.org/10.1075/ijcl.9.1.07par

Schmitt, N., \& Carter, R. (2004). Formulaicsequences in action: An introduction. In N. Schmitt (Ed.), Formulaic Sequences (pp. 1-22). Amsterdam: John Benjamins. http://dx.doi.org/10.1075/11lt.9

Sinclair, J. (1991). Corpus, Concordance, Collocation. Oxford: Oxford University Press.

Sinclair, J., Jones, S., Daley, R., \& Krishnamurthy, R. (2004). English Collocational Studies: The OSTI Report. London: Continuum.

Stewart, D. (2009). Semantic Prosody: A Critical Evaluation. London: Routledge.

Stubbs, M. (1995). Collocations and semantic profiles: On the cause of the trouble withquantitative methods. Function of Language, 2, 1-33. http://dx.doi.org/10.1075/fol.2.1.03stu

Stubbs, M. (1996). Text and Corpus Linguistics. Oxford: Blackwell.

Wei, N. (2002a). Research methods in studies of semantic prosody. Foreign Language Teaching and Research, 34, 300-307. 
Wei, N. (2002b). A Corpus-driven Study of Semantic Prosodies in Specialized Texts. Modern Foreign Languages, 25, 165-175.

Whitsitt, S. (2005). A critique of the concept of semantic prosody. International Journal of Corpus Linguistics, 10(3), 283-305. http://dx.doi.org/10.1075/ijcl.10.3.01whi

Xiao, R., \& McEnery, T. (2006). Collocation, semantic prosody, and near synonymy: A crosslinguistic perspective. Applied Linguistics, 27, 103-129. http://dx.doi.org/10.1093/applin/ami045

\section{Copyrights}

Copyright for this article is retained by the author, with first publication rights granted to the journal.

This is an open-access article distributed under the terms and conditions of the Creative Commons Attribution license (http://creativecommons.org/licenses/by/3.0/). 